\title{
10. Conclusion: learning and contestation in EU foreign and security policy
}

\author{
Niklas Bremberg, August Danielson, Elsa \\ Hedling and Anna Michalski
}

\section{LEARNING AND CONTESTATION IN EU FOREIGN AND SECURITY POLICY}

In this book, we have traced the emergence of communities of practice in various bodies and venues of the policy-making environment surrounding the European Union's (EU) Common Foreign and Security Policy (CFSP). In the last decade, several formal and informal rules have sprung up in this context, resulting in a repository of practical knowledge that is shared among practitioners in both EU institutions and member states' ministries of foreign affairs and defence. Beyond the increasing institutionalization of EU foreign and security policy, practical policy-making on the ground is truly experimental, in the sense that it is co-created by diplomats, civil servants and military personnel who throughout their careers move in and out of assignments with the task to embody and perform the EU's presence in international affairs. Regardless of whether these assignments have their bureaucratic origin in a national setting or an EU institution, or whether the practitioners alternate between wearing their national and European hats, they share the aim of making EU foreign and security policy work on the ground. For the practitioners, the co-creation of EU foreign policy has become part of their daily work, whether they are negotiating a position, deciding on the implementation of a foreign mission, coordinating standpoints on a declaration, or implementing EU foreign or security policy abroad in third country capitals and hotspots around the world. These experiences have allowed practitioners to grow accustomed to a certain way of working, acquiring a shared outlook and taking part in the creation of practical knowledge that today forms the habitus of EU foreign and security policy. Through iterative interactions, these practitioners have created communities of practice in the expanding field of EU foreign and security policy, acquiring the ability to move in and out of specific bodies with ease. It is this practical knowledge that we have aimed to capture in this book. 
However, this depiction of the practical reality of the day-to-day co-creation and actual performance of EU foreign and security policy needs to be qualified. First, despite the description above of communities of practice based on shared background knowledge and a sense of common purpose, the everyday making of EU foreign and security policy has been characterized by a growing level of dissent in recent years. Our investigation, however, has revealed that the participants, whether on the ground in foreign countries or in meetings in Brussels, find ways around blocking minorities to coordinate EU foreign and security policy. Below, we give a more precise description of what constitutes the making of EU foreign policy. Here, it suffices to say that it is based on a conviction of the importance 'to make it work', which in itself has given rise to a willingness to experiment and learn beyond the theoretical expectations of European integration theories. In addition, it is important to note that the willingness of making EU foreign policy work is located at the level of the individual and the group, not at the level of the EU institutions or the member states. In other words, the practitioners are aware of blockages on the political level and recognize these are part of a diplomat's life, but they still try to find practical ways of resolving disagreements and blockages in order to move on. That is, the communities of practice look for cohesion on the level of practical knowledge about formal and informal rules and ways of doing things, not on the level of conviction of the constitutive norms of the EU, such as the ones outlined in Article 21 of the Treaty on European Union (TEU). ${ }^{1}$ Second, the revelation that comes from the realization of how these communities make things work has implications both for the traditional tenets of socialization theory and for previous studies drawing on insights from practice approaches.

\section{THEORETICAL INSIGHTS FROM STUDYING THE EVERYDAY MAKING OF EU FOREIGN AND SECURITY POLICY}

As discussed in Chapter 4, the patterns of socialization that emerge in the EU communities of practice are not shaping individuals into 'same-mindedness' in the sense of fully internalizing the EU's constitutive norms or adopting common preferences, as is often predicted, at least implicitly, by scholars of EU socialization. However, individuals are adopting approaches to deal with recalcitrant individuals or groups who hold out and prevent consensus forming

1 These are democracy, the rule of law, the universality and indivisibility of human rights and fundamental freedoms, respect for human dignity, the principles of equality and solidarity, and respect for the principles of the United Nations Charter and international law. 
on a particular issue. Such behaviour does not necessarily have to do with the position of their member state - although that is important as well - but rather whether the individual is perceived as breaking with group norms and practices. Such a person is not considered to be 'a good diplomat'; that is, these diplomats break with the practices that allow the group to 'make it work'. The communities of practice of EU foreign and security policy can therefore be seen as based on the like-mindedness (rather than 'same-mindedness') of the individuals who participate in the coordination of policy and search for solutions.

Much of the socializing therefore takes place on two levels of learning: the first on the level of an individual - a novice - learning the practices of the group in terms of formal and informal rules and the ways in which things are done; and the second on the level of the group that explores and learns from the opportunities offered by an evolving institutional framework and imposed by a changing international order. Socialization introduces a novice into the existing social framework of a group and helps the novice to navigate the formal and informal rules. It also serves to create a sense of common purpose and the social cohesion necessary to make EU foreign and security policy work even in an atmosphere of contestation. This take on socialization is different from previous research in that dissent is treated as a fact of life for a diplomatic community, including as a potentially productive mechanism for the development of new practices to 'make it work'. The practitioners working in the bodies tasked to produce or implement EU foreign and security policy must manage disagreement when in the process of enacting their bureaucratic roles of competent diplomats. Therefore, socialization is intricately linked to learning the practices that allow the group to overcome dissent and make EU foreign policy move forward, despite growing dissent among member states.

In the framework presented in Chapter 4, non-representational knowledge (that is, practical knowledge) constitutes what practitioners think from rather than what they consciously think about. In the communities of practise that form in and around EU foreign and security policy, there is by now a body of non-reflective practices and modes of action that permit individuals to perform in line with the expectations of a competent diplomat. They also allow these individuals to move from one venue to another, from the national to the European level, and from one organ or bureaucratic setting to another. However, when it comes to learning on the level of either the individual or the group, the traditional 'Bourdieuan' way of conceptualizing practical knowledge is insufficient. In both these instances, practitioners show self-awareness of the purpose of their bureaucratic roles, the limits of formal rules and institutional settings, and the boundaries set by national sensitivities. In other words, on both the individual and group level, there is a relatively higher degree of consciousness about the practices being learned than is traditionally assumed. 
For the novice who seeks to learn the formal and informal rules and norms of inaction, practices need to be identified and revealed so that the individual can be socialized into the group. For the group, consciousness about practices and norms is an essential aspect of finding ways to overcome dissent, and solutions to unblock disagreements. As we shall see in the review of the empirical findings in this book, in the various bodies and venues of the EU this aspect of conscious experimentation and learning has become part of what the everyday making of EU foreign and security policy implies.

\section{COMPARING AND CONTRASTING COMMUNITIES OF PRACTICE}

\section{Council Working Groups}

By focusing on two comparisons - between the Working Party on Eastern Europe and Central Asia (COEST) and the Politico-Military Group (PMG), and between the PMG and the higher-ranking Political and Security Committee (PSC) - the first empirical chapter revealed that the Council Working Groups (CWGs) that prepare the CFSP are remarkably similar in terms of the norms and practices which structure their work. Therefore, both COEST and the PMG can be regarded as constituting two communities of practice. For example, the members of the two groups share a definition of what constitutes competent performance; what makes a good diplomat. This definition of competence can be summed up into six attributes: efficiency, perceptiveness, subject knowledge, language skills, 'charismatic impersonality', and having a strong mandate from one's capital.

Another finding of the chapter is that the representatives of the PMG have less previous experience of negotiating on behalf of their member states, although they perceive themselves to be more frequently engaged in high-stakes negotiations, compared to their counterparts in the PSC. Although this may simply be the result of not having enough experience with EU negotiations to correctly identify potentially risky outcomes, it may also be an effect of the lower-ranking working groups constituting the bodies where the 'real' negotiations on specific issues take place. This is also reflected in the perceptions of the representatives of the PMG and COEST that their working groups are more important than other similar working groups.

Interestingly, contestation on the political level (that is, among the EU member states) has not led to a deterioration of the atmosphere in either of the two groups. Despite increasing contestation between the member states, both groups have upheld a strong sense of cohesion and good personal relationships, including between the representatives of member states on 'both sides' of the most contentious issues. In fact, and somewhat paradoxically, the atmosphere 
within the two groups almost seems to have improved in line with decreasing cohesion among the member states, which suggests that macro-level contestation does not determine the degree to which a community of practice is able to maintain its existing practices.

\section{The Political and Security Committee}

Despite increasing contestation among member states on a number of issues such as human rights, migration, sexual and reproductive health and rights, and relations to countries such as China and Russia, the PSC has been able to uphold its main practices, such as the consensus-building practice and the coordination reflex. Similar to the lower-ranking CWGs, the representatives in the PSC place a high value on norms such as trust and transparency. These practices have allowed the PSC to remain efficient despite the increasing heterogeneity of member states' preferences during the last decade. The PSC has been able to remain internally cohesive mainly because its representatives have developed a common understanding of the value of efficiency. Given the increasing contestation on the member state level, the PSC is also a good illustration of the effects of unequal reflexivity within a community of practice. Although some practices - for example, referring to the EU acquis or appealing to the value of unity - are perceived as being devoid of normativity by the senders, this does not mean that all members of the group perceive these practices in the same non-contentious manner.

Since its inception, the PSC has gone through some major developments. The new relationship to the European External Action Service (EEAS) and the High Representative of the Union for Foreign Affairs and Security Policy and Vice-President of the European Commission (HR/VP) as well as the changing relations to the Committee of Permanent Representatives, Coreper II (member states' ambassadors to the EU) and the European Council have meant that the PSC has had to redefine its role multiple times. However, although it may not be acting in the shadows any longer, the PSC is still a crucial actor in making the CFSP work, despite the significant number of crises it has had to weather.

\section{The European External Action Service}

Ten years after its inception, the EEAS is still experiencing fragmentation and multiple social identities among its staff. Despite this, EEAS officials speak of collective efforts to 'make it work' by learning how to work together to fulfil the purpose of the EEAS. In this sense, officials do share a common normative conviction. For newcomers to the institution, it takes time to learn to navigate the maze of informal practices within the EEAS. Nevertheless, they appear 
relatively quickly to adhere to the belief of the importance of the EEAS as the cornerstone of the CFSP.

There is growing agreement of the importance of a shared understanding of the emerging practices of EEAS diplomacy. This practical knowledge is built on a network of communities of practice, in the sense that the EEAS has inherited ways of doing things from existing institutional legacies, which have merged with practices organically developed through deliberate reflection and experimentation. Although the much-awaited development of new practices in crisis management is still hindered by member states' reluctance to delegate, other less traditional areas of foreign policy have produced new repertoires of practical knowledge, such as in strategic communication and coordination efforts emerging as a result of the COVID-19 pandemic.

The bureaucratic environment of the EEAS exhibits an interplay between practices and socialization that can best be described in terms of multiple processes that simultaneously produce sustained contestation and gradual practical habituation of common practices. This combination of social learning and contestation has become institutionalized through coping practices. In addition to learning according to the internal logic of EEAS, practical learning has turned into a strategy to manage the relationship to the EU institutions and the member states, and as a guiding principle in the practices of coordination. By promoting opportunities to learn, cohesion through learning, and the legitimation of experimental learning, the EEAS has managed to establish an actively passive role in EU foreign policy.

\section{The EU Delegations and Coordination in Third Country Capitals}

Intense coordination to enact EU foreign and security policy between the EU delegation and the member state embassies has become common practice and is now taken for granted in third country capitals. Among member state diplomats, especially from the small and middle-sized EU members, the recognition of the value of acting together and the protection in numbers is growing.

Over the last ten years, member states have grown increasingly at ease with the practices of coordination and representing the EU as well as their home country in third country capitals. Even in traditionally bilateral capitals such as Washington and Beijing, there is less a sense that national and European foreign policy necessarily stand against each other. Instead, there is an increasing awareness of the importance for member states to represent the EU abroad. Especially in Washington under President Donald Trump, member state diplomats made a conscious decision to stand up for the EU in consultations with US officials. It is clear that conscious decisions have been made by member state diplomats to solidify the presence of the EU abroad in the defence of EU foreign and security policy. At the same time, there is no illusion or hesitancy 
about the fact that bilateral relations continue to be important. Rather, the coordination of EU foreign and security policy abroad seems to have reached a stage of normalcy, as member state and EU diplomats have found ways of making the implementation work so that it is acceptable to both.

Forming communities of practice abroad not only relies on reiterative learning processes that initiate newcomers to the informal and formal rules and ways of working, but also allows the groups to adapt to the local environment as well as changes in EU foreign and security policy. For practitioners, both general and specific knowledge of diplomatic practices are considered very important. This practical knowledge also permits diplomats to move from one locality of coordination abroad to another, as well as back to the national capital or even Brussels. These diplomats have acquired an acute awareness of informal (and formal) rules and expectations vis-à-vis one another.

Dissention in third country capitals, to a point, is handled through the adherence to precedence in terms of the substance (policy) of what is coordinated and conveyed to host country representatives. In this sense, the acquis emanating from Brussels helps to defuse dissent, as no negotiations or decisions on substance need to be taken abroad. Also important is how the formal division of competences steers the action of the EU delegations abroad and delineates who does what in third country capitals, in an attempt to minimize the problem of turf battles.

Practitioners based in EU delegations have a strong sense of what makes a good diplomat. Above all, a seasoned diplomat knows what is expected and skilfully masters various diplomatic practices. Beyond basic diplomatic know-how, experience from other contexts, especially EU institutions or even multilateral organizations such as the United Nations (UN) or the North Atlantic Treaty Organization (NATO), informs diplomats about what to do in third country capitals, and how to understand the purpose and practices of EU coordination. This points towards an emerging community of practice that goes beyond the particular location where a diplomat is based, indicating a more general habituation of the norms and practices that define the field of EU foreign and security policy.

\section{EU Missions and Operations Abroad}

The EU has undertaken several Common Security and Defence Policy (CSDP) missions and operations over the years. In this area, repeated interaction has led to the emergence of multiple communities of practice around shared understandings of what it means to enact EU foreign and security policy, and how to learn from past missions and operations. In a way that is somewhat different from bodies in Brussels or in third country capitals, these communities of practice reflect the cultures of cooperation across international security frame- 
works in which the EU participates, most notably the UN and NATO. Many CSDP officials have military backgrounds, and engage in practices that largely build on previous military practices that have been adapted to and evolve through the interaction with civilian staff. That is, a rather distinctive culture has emerged in the EU around 'learning to learn' what it means to conduct CSDP missions and operations.

Learning in the field of CSDP missions takes place foremost through informal practices, and through the disposition, knowledge and skills newcomers bring with them from previous (related) postings. Since the launch of the Global Strategy in 2016, lessons learning processes have become a prioritized activity within the CSDP, but have been hampered by the fragmentation across different communities of practice, the crowded institutional landscape, the difficulties of recording informal practices, and the political sensitivity surrounding questions of security and defence among the member states. In recent initiatives, the EU has attempted to create a more coherent approach to knowledge management. Despite the constraints, CSDP officials share the perception that the COVID-19 pandemic has revealed a common ground for learning processes and knowledge management that has already resulted in successful coordination practices.

\section{TOWARDS A EUROPEAN COMMUNITY OF PRACTICE IN FOREIGN AND SECURITY POLICY}

In this book, we have systematically investigated several relevant bodies and venues of the everyday making of EU foreign and security policy; analyses that have revealed the existence of various and partly overlapping communities of practice. These communities of practice are shaped to correspond to the specific purposes and tasks they have been entrusted with, by their position in the institutional structure and by the profile of the individuals who work within them. However, these communities of practice are also shaped by the evolving interactions among practitioners with various backgrounds and experiences. Nevertheless, many aspects have been revealed that play an important role in creating, adapting and developing the way in which these groups maintain cohesiveness, purposefulness and flexibility in a changing internal and external context.

\section{Ability and Willingness to Learn}

In all venues investigated in this book, the groups have displayed a strong ability to learn and a willingness to find ways to make the EU foreign and security policy work. Even individual diplomats who are given mandates from their capitals to hold out on a certain issue, in order to block a common position, can 
do this in a way that is acceptable to other members of the group and without completely impeding the interaction of the group or future agreements. Put simply, the members of these groups have learned the practices of diplomatic engagement that allow them to distinguish between an individual's behaviour and the duty of a diplomat to represent national positions. This has allowed the groups meeting in Brussels to develop their practices of interaction at arm's length from the bickering in the capitals of member states. The group's cohesion to a certain extent depends on the members' ability to learn these practices as newcomers, as well as to continue adhering to them as more seasoned diplomats. The pattern is similar in missions abroad and in third country capitals, where having acquired the practical knowledge of informal and formal rules is a prerequisite for participating in the conduct of the missions, or in the coordination of EU foreign and security policy. Practitioners who have the diplomatic skills and know the practices of interaction are considered good diplomats; that is, diplomats who have internalized the shared definition of competent performance.

Another way in which the knowledge of practices is important is for the group to adapt and develop practices either because of changed circumstances or because the group believes that their working methods have become counterproductive or inadequate for the tasks at hand. In our empirical investigations, we found that these groups, which shape or implement EU foreign and security policy, report a reflexive introspection of their practices and norms. That is, they seek to make EU foreign policy work, and reflect on what they can do to improve their working methods. They are also acutely aware of the boundaries set by the EU treaties, or member states' reluctance to delegate additional competences to joint decision-making, which contrasts with conventional understandings of how practices are learned. Rather, we found that this reflective character of practical learning enabled the members of the group to jointly learn, experiment and develop new ways of interacting and working together.

\section{Making it Work Despite Dissent among Member States}

As we state in Chapter 1 of this book, it is an intriguing observation that despite the extent of disagreement among the EU member states on many issues of foreign and security policy, the CFSP is still working. There is even a convincing case to make that EU foreign and security policy is expanding, possibly even becoming more forceful and decisive. On the micro level, which is the primary focus of this book, there are several aspects that contribute to the everyday making of EU foreign and security policy: the ability of practitioners, individually or as a group, to adapt the practical ways of working through conscious reflection on ways to improve them; the ability of individuals to 
socialize to the formal and informal rules of a group; and a high degree of self-awareness and willingness to make EU foreign and security work. In the parlance of diplomats, good diplomats competently perform the group's practices, socialize to the working methods and norms of the group, and balance the interests of their member state with the interests of the group.

\section{Socialization and Sense-Making of Diplomatic Practices}

The empirical investigations in this book show that socialization does not necessarily lead to 'sameness'. They also show, however, that 'sameness' is not a necessary condition for the EU foreign and security policy to function. Just as members of groups in Brussels socialize to formal and informal rules, so they also develop a sense for what practices they should learn and how they should be enacted to be considered a competent diplomat. The communities of practice in EU foreign and security policy do not need to fully internalize the EU's mission to fulfil their tasks; on the other hand, they do adhere to the credo of making EU foreign policy work, and show a willingness to reinvent the practical knowledge of being an EU diplomat to make this happen. In other words, the level of conscious reflection on developing common practices to shape and implement EU foreign and security policy, as well as maintaining a balance between national and European interests, indicate that diplomats, civil servants and military personnel are engaged in a process of sense-making of the currently existing practices of the CFSP. This became especially clear throughout our interviews, as the respondents themselves often expressed a strong willingness to discuss their practices, sometimes only as a therapeutic exercise, but at other times as an explicitly instrumental way of learning what works and what does not work.

\section{AVENUES FOR FUTURE RESEARCH}

We believe that our book illustrates the theoretical, methodological and empirical benefits of applying and combining insights from socialization theory and practice approaches to explore the everyday making of EU foreign and security policy. By way of suggesting avenues for future research, we would like to highlight three that we think are particularly promising.

First, in terms of methodological advancements, we think that our approach, which has relied on a mix of data sources, has been proven well suited for our research aims, but we also think that it is worth exploring other ways of studying European diplomatic practices. Semi-structured interviews are certainly useful, especially since participant observation and other more demanding ethnographic methods are often difficult to apply for researchers in sensitive and restricted fields of study, such as foreign and security policy. However, 
it is not the only method available to study practices. For example, carefully reconstructing individual career paths of EU diplomats and officials could be one way of mapping the formation of communities of diplomatic practice, and in-depth process-tracing of how certain EU decisions and policies came about might reveal how informal and formal practices shape policy outcomes in EU foreign and security policy. As shown in Chapter 5, individual-level data on variables related to negotiations can also be combined with qualitative data, as quantitative analyses may help us to probe potential explanations for the development of practices and group identities that otherwise would remain undetected and undertheorized. Moreover, the rapid expansion of digital practices of diplomacy in the EU and elsewhere will likely provide researchers with new empirical data to analyse and explore.

Second, as many of the dominating trends in international politics seem to be moving in a distinctively post-Western direction, we think that it is highly pertinent to explore new ways of thinking about what this means for the study of EU foreign and security policy. The EU has always prided itself on its ability to demonstrate that it is possible to transcend historical animosities and great power competition, but there is a growing awareness among researchers in international relations and EU studies that the legacy of European colonial expansion and rule is still being felt in many parts of the world, including within European societies. These important concerns should be considered when we think of ways in which to advance the study of the everyday making of EU foreign and security policy. For example, what notions (if any) of European colonial rule are shaping practical knowledge about what can and cannot be done in EU external action vis-à-vis non-European countries? To what extent are the boundaries of European communities of diplomatic practice structured along gendered and racialized hierarchies? And how are notions of 'European values' enacted in the everyday making of EU foreign and security policy?

Finally, while our book has covered various communities of practice centred around CWGs, the PSC, the EEAS, EU delegations in Washington and Beijing, as well as the CSDP, there are ample opportunities to further explore how communities of practice shape interactions in other organs and venues in EU foreign and security policy. It would be of particular empirical relevance, for example, to do so in relation to policy fields such as developmental assistance, cyber governance, humanitarian aid and climate change mitigation, especially since the EU is an important actor and is expanding its commitments in these fields. It would also be of great empirical interest to deepen our understandings on how communities of practice are shaping EU foreign policy actions vis-à-vis other global powers such as Brazil, China, India, Russia and Turkey; as well as how and to what extent communities of practice centred around venues in the EU also overlap with venues in other international organizations, such as the UN, NATO and the Organization for Security and 
Co-operation in Europe (OSCE). Making such cross-case comparisons would likely advance our knowledge on how and under what conditions international crisis management is done in practice. 